\title{
Análise de blocos de fundação destinados ao apoio de pilares de geometria complexa
} Analysis of pile caps designed to support columns of complex geometry

\section{Análisis de elementos de cimentación diseñados para soportar columnas de geometría compleja}

SOUZA, Rafael Alves de ${ }^{1}$ BAVARESCO, Danicler ${ }^{2}$ PALHARINI JUNIOR, Dionisio ${ }^{3}$ TRAUTWEIN, Leandro Mouta ${ }^{4}$

1Departamento de Engenharia Civil, Universidade Estadual de Maringá, Maringá, Brasil. ORCID: 0000-0002-9990-2850.rsouza@uem.br 2Departamento de Engenharia Civil, Universidade Estadual de Maringá, Maringá, Brasil. ORCID: 0000-0002-7461-9725. engenheirobavaresco@gmail.com 3Departamento de Engenharia Civil, Universidade Estadual de Maringá, Maringá, Brasil. ORCID: 0000-0001-8616-7386. dionisiopalharini@gmail.com ${ }^{4}$ Departamento de Estruturas, Universidade Estadual de Campinas, Campinas, Brasil. ORCID: 0000-0002-4631-9290. leandromt@fec.unicamp.br 


\title{
Resumo
}

O presente trabalho tem por objetivo estudar o comportamento de blocos de fundação sobre estacas que recebem pilares de geometria complexa. Procura-se avaliar se o dimensionamento simplificado desses casos, utilizando o Método das Bielas, pode ser feito através da substituição da geometria complexa do pilar por uma seção quadrada, rotina essa frequentemente utilizada nos programas comerciais de dimensionamento automático e cercada de grandes dúvidas nos escritórios de projetos estruturais. Para tanto, foram efetuadas análises numéricas para três formatos de pilares (Retangular, em $\mathrm{L}$ e em $\mathrm{C}$ ) e duas configurações de bloco (cinco e nove estacas). $\mathrm{Na}$ análise dos diferentes tipos de pilares, verificou-se que a consideração de geometria complexa gerou uma distribuição mais homogênea dos esforços nos blocos de fundação, resultando em campos de tração inferiores e consequentemente em menores taxas de armadura de tração quando comparados com a seção quadrada equivalente. Finalmente, para os blocos de fundação com pilares de geometria complexa investigados, verificou-se que a simplificação da geometria complexa do pilar por uma seção quadrada equivalente pode ser considerada a favor da segurança devido a maior quantidade de armaduras necessárias, validando assim a rotina normalmente adotada de maneira rotineira nos escritórios.

Palavras-Chave: Método das Bielas; Blocos de Fundação; Pilares; Análise Numérica.

\begin{abstract}
The present work has the purpose of studying the behavior of piles caps to support columns of complex geometry. It is evaluated if the simplified designed of columns with complex geometry, using the Strut and Tie Method, can be adopted by replacing the complex geometry of the column to a square section, a routine that is frequently used and surrounded by doubts at offices of structural engineering. Numerical analyzes were performed for three columns formats (Rectangular, $L$ and $C$ ) and two piles caps with five and nine piles. In the analysis of the different types of geometries, it was verified that the consideration of complex geometry generated a homogeneous distribution of stresses in the piles caps, resulting a lower tension fields and consequently lower rates of reinforcement when compared with the square section equivalent. Finally, for the piles caps with complex geometry columns, it was verified that the simplification of the complex geometry column by an equivalent square section can be considered in favor of security taking into account the higher quantity of reinforcement, validating the usual routine adopted in the structural offices.
\end{abstract}

Key-Words: Strut and Tie Model; Pile Caps; Columns; Numerical Analysis.

\section{Resumen}

El presente trabajo tiene el objetivo de estudiar el comportamiento de zapatas para soportar columnas de geometría compleja. Se evalúa si el diseño simplificado de columnas con geometría compleja, utilizando el Método de Bielas y Tirantes, puede realizarse reemplazando la geometría compleja de la columna por una sección cuadrada, una rutina utilizada frecuénteme en programas comerciales de dimensionamiento automático y rodeada de dudas en las oficinas de ingeniería estructural. Se realizaron análisis numéricos para tres formatos de columnas (Rectangular, $L$ y C) y dos configuraciones de zapata con cinco y nueve pilotes. En el análisis de los diferentes tipos de geometrías, se verificó que la consideración de la geometría compleja generaba una distribución homogénea de tensiones en los grupos de pilotes, lo que resulta en campos de tensión más bajos y, en consecuencia, tasas de refuerzo más bajas en comparación con el equivalente de sección cuadrada. Finalmente, para las zapatas con columnas de geometría compleja, se verificó que la simplificación de la columna de geometría compleja por una sección cuadrada equivalente puede considerarse a favor de la seguridad teniendo en cuenta la mayor cantidad de refuerzo, validando la rutina habitual adoptada en las oficinas estructurales.

Palabras clave: Método de Bielas y Tirantes; Zapata; Columnas; Análisis numérico. 


\section{Introdução}

Os blocos de fundação são elementos volumétricos localizados nas bases dos pilares e são responsáveis por transmitir os esforços da superestrutura às estacas ou tubulões. Estes elementos são de extrema importância para a solidez e segurança das estruturas e, devido sua localização enterrada, se caracterizam por estruturas de difícil inspeção e monitoramento.

Embora os blocos de fundação sejam elementos muito comuns nas edificações, não há um consenso sobre como estes elementos devem ser dimensionados (SOUZA et al., 2009). Basicamente, dois procedimentos têm sido adotados com frequência para o dimensionamento de blocos de fundação: Modelo de Viga e o Método das Bielas (ADEBAR et al., 1990; IYKER e SAM, 1992; SAM e IYKER, 1995; CHAN e POH, 2000).

As instruções normativas mais recentes têm acenado para utilização do Método das Bielas para o projeto de blocos rígidos sobre estacas (ACl-318, 2019; ABNT NBR 6118, 2014). Este método consiste na concepção de treliças tridimensionais, formadas por elementos comprimidos (escoras) que representam os campos de compressão, elementos tracionados (tirantes) que representam os campos de tração e os nós representando as regiões de transmissão das forças (SCHÄFER e SCHLAICH, 1991).

O método proposto por Blevot e Frémy (1967) é a base para maioria dos modelos de dimensionamento de blocos de fundação sobre estacas (MIGUEL, 2000; SOUZA, 2004; DELALIBERA, 2006). A partir de dois extensos programas experimentais, os referidos autores apresentaram vários modelos de treliça para o dimensionamento de blocos de fundação sobre duas a cinco estacas, além de recomendações práticas para caracterização geométrica e disposição das armaduras.

Tendo em vista que os modelos propostos por Blevot e Frémy (1967) foram desenvolvidos considerando pilares de seção quadrada, torna-se questionável o uso deste método para os casos de pilares com geometria complexa. Tendo-se em vista a modernização dos métodos de cálculo, tem-se observado na última década a crescente utilização de pilares-parede em regiões como caixas de elevadores, caixas de escada e núcleos rígidos de edifícios, de maneira a travar globalmente edificações altas, conforme ilustra a Figura 1.

Figura 1: Exemplos de pilares de geometria complexa com destaque para região de elevadores.

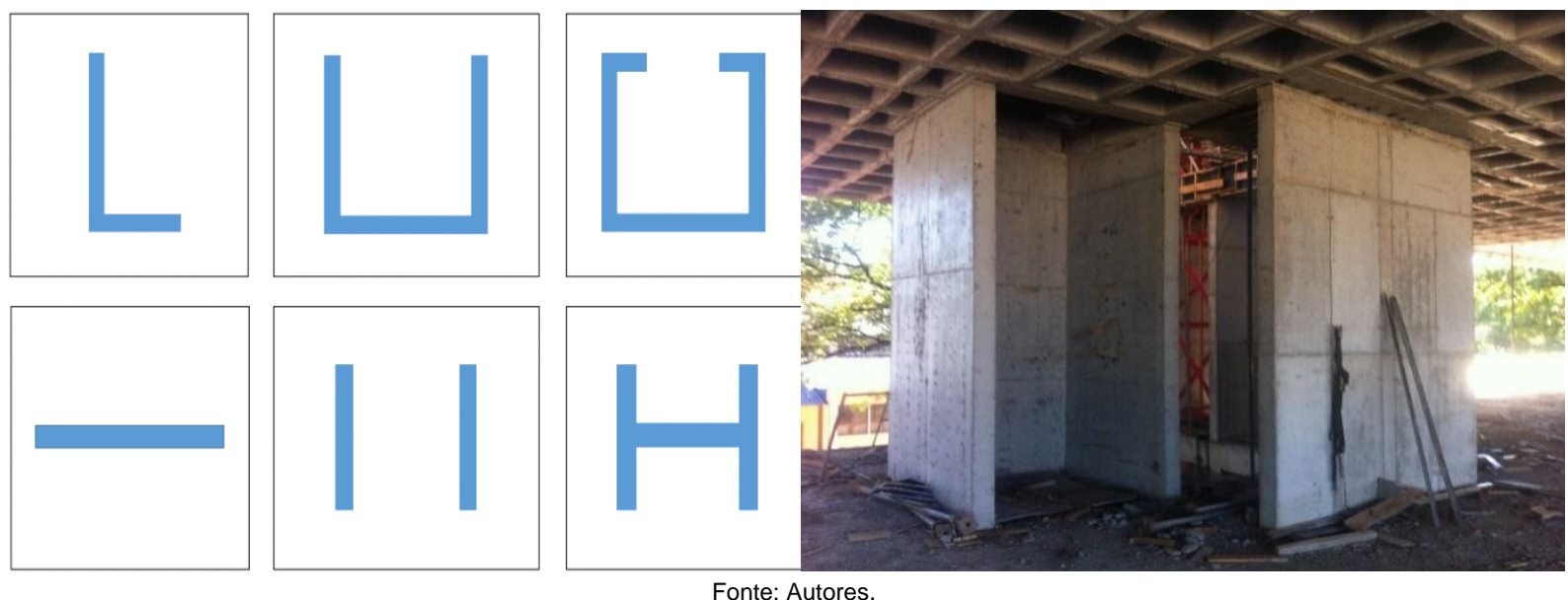

O fato é que para pilares de geometria complexa, o centro de gravidade muitas vezes não cai sobre as próprias paredes, como é o caso de um pilar em L ou em C. Para pilares com essa característica, existe uma tendência de substituição da geometria complexa por um pilar de forma quadrada com área equivalente ao pilar de geometria complexa, de maneira a ser possível utilizar a formulação de Blevot e Frémy (1967) de maneira adaptada. 
Apesar de ser um procedimento aparentemente frequente nos escritórios de cálculo, fica sempre a dúvida se o dimensionamento utilizando tal simplificação encontra-se contra ou favor da segurança, uma vez que o nível de ocupação dos pilares complexos sobre os blocos é normalmente mais distribuído, com possibilidade de surgimento de bielas mais abatidas e níveis de tensão diferenciados em relação aos obtidos para um simples pilar quadrado de seção equivalente.

Engenheiros projetistas com maior domínio sobre o Método das Bielas tendem a desenvolver modelos de treliça mais específicos, conforme ilustra a Figura 2a, ao invés de utilizarem a simplificação de se adotar uma seção quadrada equivalente, conforme ilustra a Figura $2 b$. No entanto, o tempo necessário de análise nesses casos acaba sendo significativamente maior do que o tempo necessário na simples definição de uma seção quadrada equivalente em um programa computacional de dimensionamento/detalhamento automático de armaduras.

Figura 2: a) Desmembramento em regiões; b) Simplificação por seção quadrada equivalente.
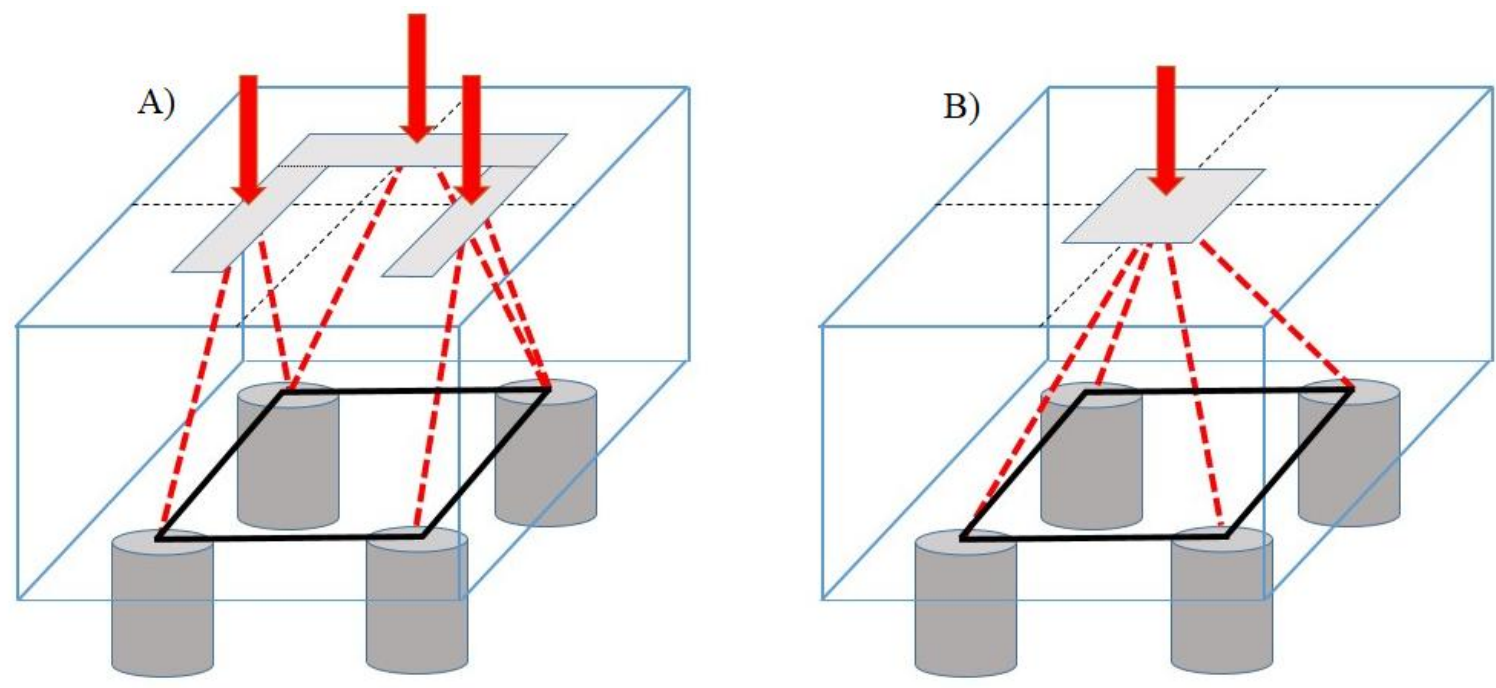

Fonte: Autores.

Do ponto de vista numérico, o pilar de geometria complexa também poderia ser simulado dividindo-se o mesmo em trechos, separados por espaçamentos de cerca de $1,0 \mathrm{~cm}$. Com essa alternativa de dividir os pilares-paredes em segmentos, pode-se obter a carga efetiva que migrará para cada um dos trechos e assim ter maior entendimento das condições de carregamento dos modelos de treliça a serem desenvolvidos.

No entanto, tal alternativa também pode ser trabalhosa e pode requerer uma resposta final baseada em uma envoltória de modelos para a definição das armaduras principais. Por exemplo, para o problema ilustrado na Figura 2, a armadura a ser adotada para os tirantes principais com essa metodologia seria a junção do resultado de três blocos sobre duas estacas definidos para os trechos do pilar-parede. Além disso, em relação às tensões de compressão das escoras, as simplificações adotadas trariam dúvidas em relação aos valores efetivamente autuantes.

Dessa maneira, em vista das dúvidas existentes em relação ao dimensionamento de blocos sobre estacas suportando pilares de geometria complexa, o presente trabalho tem por objetivo avaliar as tensões desenvolvidas nesses tipos de elementos utilizando análises numéricas. Tendo-se em vista que o ensaio de blocos de fundação é dificultado em vista das dimensões e forças envolvidas, a análise numérica tem se configurado como um verdadeiro laboratório virtual, auxiliando no melhor entendimento desses elementos de natureza complexa (SOUZA, 2004; SOUZA e BITTENCOURT, 2006; SOUZA et al., 2007). A ABNT NBR 6118 (2014), em seus itens 14.8.2 e 22.7.3, também 
recomenda a utilização da análise linear, inclusive modelos tridimensionais, através do método dos elementos finitas ou das diferenças finitas para a avaliação dos esforços atuantes em blocos de fundação.

\section{Metodologia}

Para o estudo do efeito da geometria do pilar sobre os blocos de fundação, foram escolhidos três formatos de pilares: em "C", em "L" e o terceiro de seção quadrada equivalente aos anteriores. Para cada tipo de pilar foram testados blocos de fundação com dois números de estacas (cinco e nove), conforme ilustra a Figura 3.

Figura 3: Disposição das estacas nos blocos de fundação investigados.

Bloco B05

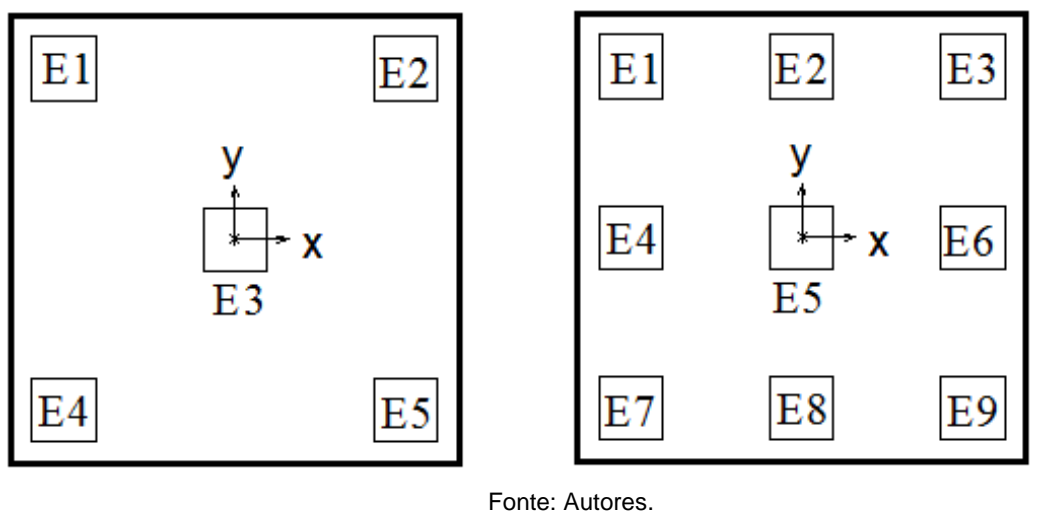

O carregamento dos pilares foi composto apenas por uma carga vertical uniformemente distribuída nas seis simulações efetuadas, bem como procurou-se posicionar o centro de gravidade dos pilares de maneira coincidente com o centro de gravidade dos blocos de fundação.

Determinada a conjuntura das seis configurações propostas, estas foram submetidas a análises elásticas lineares tridimensionais utilizando o programa SAP2000 (CSI, 2013). O software foi escolhido por ser um programa muito difundido nos escritórios de cálculo estrutural no Brasil, bem como pela facilidade de visualização das tensões em elementos tridimensionais através de cortes nas posições de interesse.

Para as dimensões dos pilares, foi definido que o pilar quadrado P01 teria dimensões de 1,00 x 1,00 m. Dessa maneira, as dimensões do pilar P02 em "C" e do pilar P03 em "L", foram definidas de tal modo que suas áreas ficassem próximas à área do pilar P01, conforme a Figura 4.

Figura 4: Geometria dos pilares investigados.
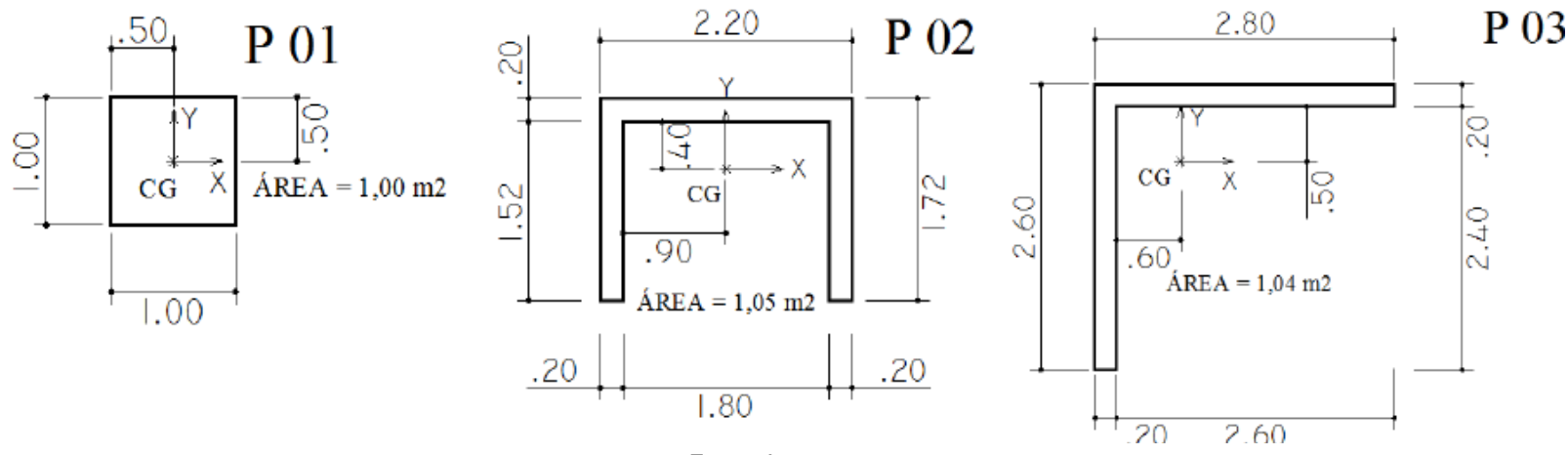

Fonte: Autores.

As estacas foram adotadas com dimensões de $0,60 \times 0,60 \mathrm{~m}$, sendo que a geometria quadrada foi definida de maneira a facilitar a modelagem por elementos finitos prismáticos, facilitando a 
continuidade dos elementos da malha. O espaçamento entre estacas foi definido em 1,60 m, com a distância entre a face da estaca e a face lateral do bloco igual a 0,20 m.

A altura dos blocos foi definida para que fosse mantida uma inclinação do campo de compressão do pilar até à estaca mais afastada próxima a 45으, também de maneira a se obter um bloco de comportamento rígido. Dessa forma, a geometria em planta ficou com 4,20 x 4,20 m e altura de 2,10 $\mathrm{m}$, conforme a Figura 5.

Figura 5: Dimensões dos blocos de fundação.

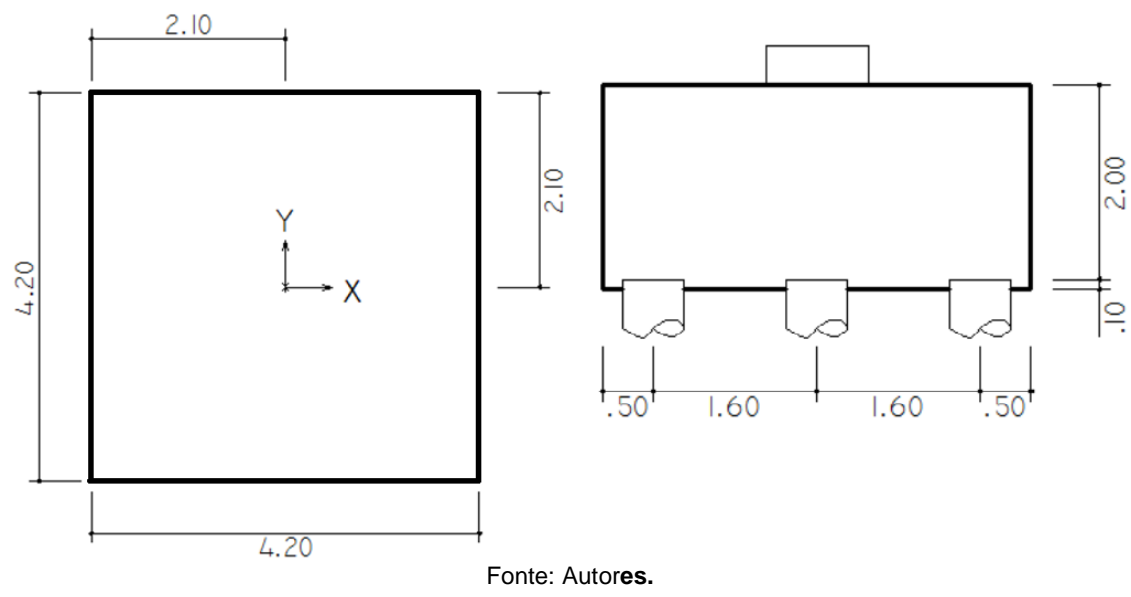

A Tabela 1 procura apresentar as características dos modelos numéricos analisados, ilustrando a nomenclatura adotada, a característica geométrica dos pilares e o número de estacas para cada uma das situações investigadas.

Tabela 1: Características dos blocos de fundação sobre estacas investigados numericamente.

\begin{tabular}{llll}
\hline № & BLOCO & SEÇÃO DO PILAR & № DE ESTACAS \\
\hline 01 & B05P01 & Quadrada & 5 \\
02 & B09P01 & Quadrada & 9 \\
03 & B05P02 & "C" & 5 \\
04 & B09P02 & "C" & 9 \\
05 & B05P03 & "L" & 5 \\
06 & B09P03 & "L" & 9 \\
\hline \multicolumn{2}{c}{ Fonte: Autores. }
\end{tabular}

Para o material das estacas e do bloco de fundação foi considerado concreto com resistência característica à compressão (fck) de $30 \mathrm{MPa}$, coeficiente de Poisson 0,2 , módulo de elasticidade de 28 GPa e peso específico de $25 \mathrm{kN} / \mathrm{m}^{3}$.

Para o carregamento da estrutura, definiu-se uma carga aplicada dos pilares sobre o bloco de 10.000 kN. Esse valor foi atribuído considerando que cada pilar teria em média 20 andares de contribuição, com uma área de influência igual a $50 \mathrm{~m}^{2}$ e carga total média de $10,0 \mathrm{kN} / \mathrm{m}^{2}$.

A aplicação da carga no bloco ocorreu pelo lançamento de uma força distribuída por área, sendo utilizado para isso a modelagem de uma placa rígida com o formato referente ao pilar. Na modelagem dos blocos, não foi considerado o comprimento de embutimento das estacas, de maneira que a altura 
adotada para os blocos foi de $2,10 \mathrm{~m}$.

$\mathrm{Na}$ modelagem das estruturas no programa SAP2000 utilizou-se o elemento finito solid, tanto para a modelagem do bloco quanto para modelagem das estacas. A placa para aplicação da carga no bloco foi modelada como sendo um elemento extremamente rígido, de maneira a simular os pés dos pilares na intersecção com os blocos de fundação. As estacas foram modeladas com comprimento de um metro e, para as vinculações, todos os nós da base das estacas foram restringidos a rotação e a translação em torno dos três eixos.

Para que a comparação entre os blocos de fundação fosse feita de tal modo em que a única variação fosse a geometria dos pilares, definiu-se que as modelagens seriam feitas utilizando elementos de $10 \times 10 \times 10 \mathrm{~cm}$, mantendo-se as malhas constantes em todas as simulações. Esta definição foi feita para que o custo computacional não fosse elevado, uma vez que testes iniciais demonstraram que a malha assim definida levaria a resultados adequados. A observação que validou o uso da malha foi o delineamento suave obtido nas linhas dos campos de tração e compressão, além de uma definição satisfatória das regiões nodais. As seis situações investigadas no programa SAP2000 são apresentadas em maiores detalhes na Figura 6.

Figura 6: Blocos de fundação simulados no programa SAP2000.
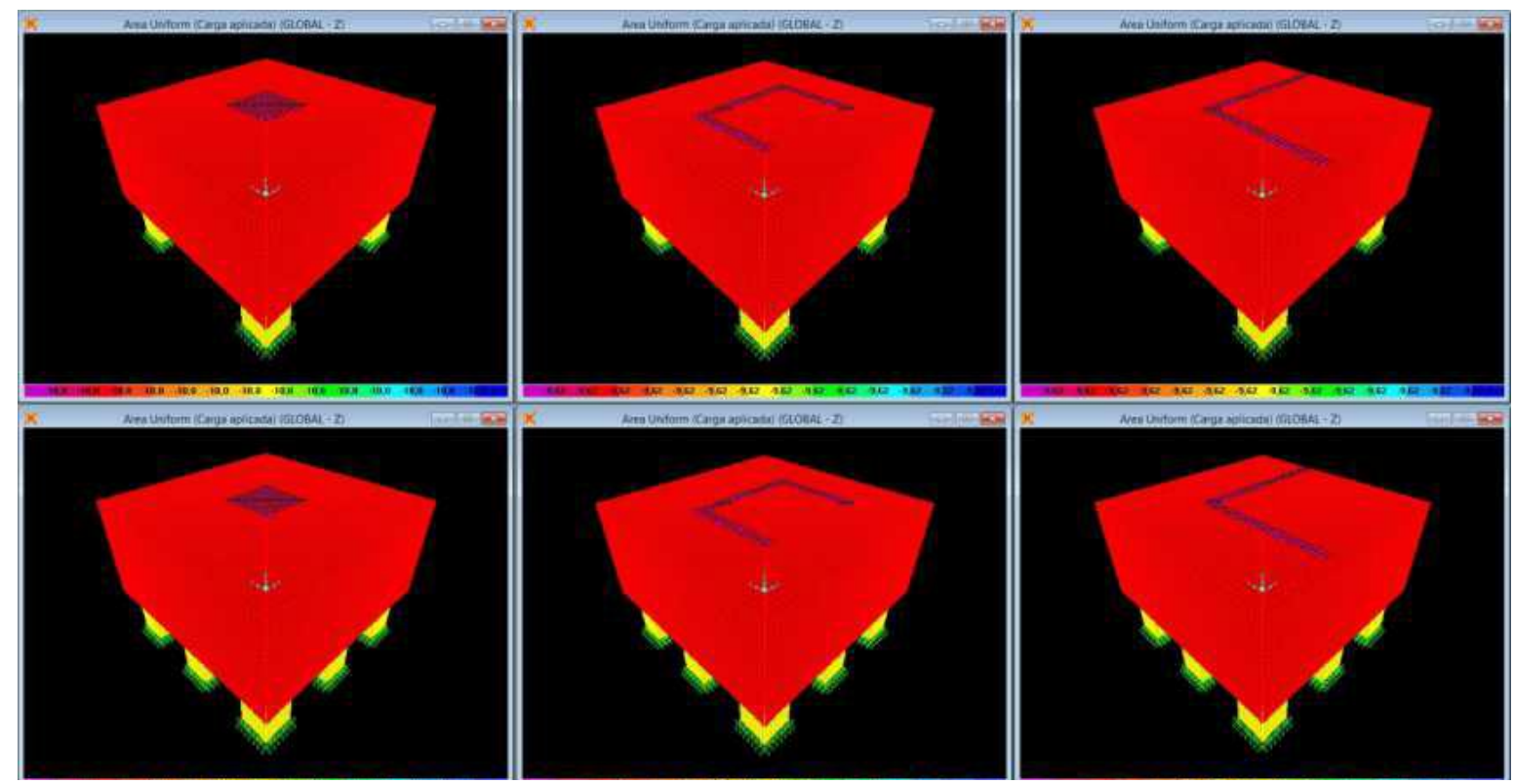

Fonte: Autores

\section{Resultados e Discussões}

Após o processamento das estruturas no programa SAP2000, procurou-se avaliar as reações de apoio em cada estaca, para todas as simulações. Essa análise permitiu avaliar qual parcela do carregamento vai para cada uma das estacas, dando uma prévia do encaminhamento das cargas para formação das escoras e regiões nodais. As Tabelas 2 e 3 apresentam os valores obtidos para os blocos de cinco e nove estacas, respectivamente, observando que o peso próprio dos blocos e das estacas encontramse embutidos nas reações obtidas e por isso a soma dos valores das estacas ultrapassa a carga total aplicada aos pilares de $10.000 \mathrm{kN}$. 
Tabela 2: Reação de apoio em cada estaca para o bloco B05.

\begin{tabular}{|c|c|c|c|c|c|c|}
\hline \multirow{3}{*}{ ESTACA } & \multicolumn{6}{|c|}{ REAÇÃO NAS ESTACAS } \\
\hline & \multicolumn{2}{|l|}{ B05P01 } & \multicolumn{2}{|l|}{ B05Р02 } & \multicolumn{2}{|l|}{ В05Р03 } \\
\hline & Valor $(\mathrm{kN})$ & $\begin{array}{l}\text { \% da carga } \\
\text { total }\end{array}$ & Valor (kN) & $\begin{array}{l}\text { \% da carga } \\
\text { total }\end{array}$ & Valor $(\mathrm{kN})$ & $\begin{array}{l}\text { \% da carga } \\
\text { total }\end{array}$ \\
\hline E1 & $2.043,83$ & $18,09 \%$ & $2.115,91$ & $18,73 \%$ & $1.955,34$ & $17,31 \%$ \\
\hline E2 & $2.043,85$ & $18,09 \%$ & $2.115,93$ & $18,73 \%$ & $2.278,82$ & $20,17 \%$ \\
\hline E3 & $3.122,43$ & $27,64 \%$ & $2.892,13$ & $25,60 \%$ & $2.831,73$ & $25,06 \%$ \\
\hline E4 & $2.043,85$ & $18,09 \%$ & $2.086,92$ & $18,47 \%$ & $2.278,93$ & $20,17 \%$ \\
\hline E5 & $2.043,83$ & $18,09 \%$ & $2.086,91$ & $18,47 \%$ & $1.952,98$ & $17,29 \%$ \\
\hline
\end{tabular}

Fonte: Autores.

Tabela 3: Reação de apoio em cada estaca para o bloco B09.

\begin{tabular}{|c|c|c|c|c|c|c|}
\hline \multirow{3}{*}{ ESTACA } & \multicolumn{6}{|c|}{ REAÇÃO NAS ESTACAS } \\
\hline & \multicolumn{2}{|l|}{ B09P01 } & \multicolumn{2}{|l|}{ В09Р02 } & \multicolumn{2}{|l|}{ В09P03 } \\
\hline & Valor & $\begin{array}{l}\% \text { da carga } \\
\text { total }\end{array}$ & Valor & $\begin{array}{l}\% \text { da carga } \\
\text { total }\end{array}$ & Valor & $\begin{array}{l}\% \text { da carga } \\
\text { total }\end{array}$ \\
\hline E1 & $1.031,23$ & $9,09 \%$ & $1.092,07$ & $9,62 \%$ & 974,73 & $8,59 \%$ \\
\hline E2 & $1.341,81$ & $11,82 \%$ & $1.292,99$ & $11,39 \%$ & $1.298,97$ & $11,45 \%$ \\
\hline E3 & $1.031,24$ & $9,09 \%$ & $1.092,08$ & $9,62 \%$ & $1.260,85$ & $11,11 \%$ \\
\hline E4 & $1.341,81$ & $11,82 \%$ & $1.407,64$ & $12,40 \%$ & $1.329,13$ & $11,71 \%$ \\
\hline E5 & $1.856,02$ & $16,36 \%$ & $1.637,77$ & $14,43 \%$ & $1.585,76$ & $13,97 \%$ \\
\hline E6 & $1.341,81$ & $11,82 \%$ & $1.407,64$ & $12,40 \%$ & $1.365,86$ & $12,04 \%$ \\
\hline E7 & $1.031,24$ & $9,09 \%$ & $1.089,69$ & $9,60 \%$ & $1.265,54$ & $11,15 \%$ \\
\hline E8 & $1.341,81$ & $11,82 \%$ & $1.238,65$ & $10,91 \%$ & $1.326,53$ & $11,69 \%$ \\
\hline E9 & $1.031,23$ & $9,09 \%$ & $1.089,68$ & $9,60 \%$ & 940,84 & $8,29 \%$ \\
\hline
\end{tabular}

Fonte: Autores.

Percebe-se pela Tabela 2 e 3 que houve uma distribuição mais homogênea das reações de apoio para os blocos que recebem os pilares de geometria complexa, quando comparados com os pilares de seção quadrada equivalente, demonstrando que os pilares de geometria complexa adotados, apresentaram melhor capacidade para distribuir os esforços para os apoios.

Para a análise dos campos de compressão, foram feitos cortes verticais nas estruturas processadas e foram analisados considerando as condições de simetria. O primeiro pilar analisado foi o Pilar P01, onde os campos de compressão obtidos são apresentados nas Figuras 7 e 8, para os blocos de cinco e nove estacas, respectivamente. Observando a intensidade dos campos de compressão, é possível notar que a escora mais carregada é a que desce para a estaca central, em ambos os blocos, como verificado observando as reações de apoio das estacas. 
Figura 7: Campos de compressão ao longo do corte AA da estrutura B05P01.

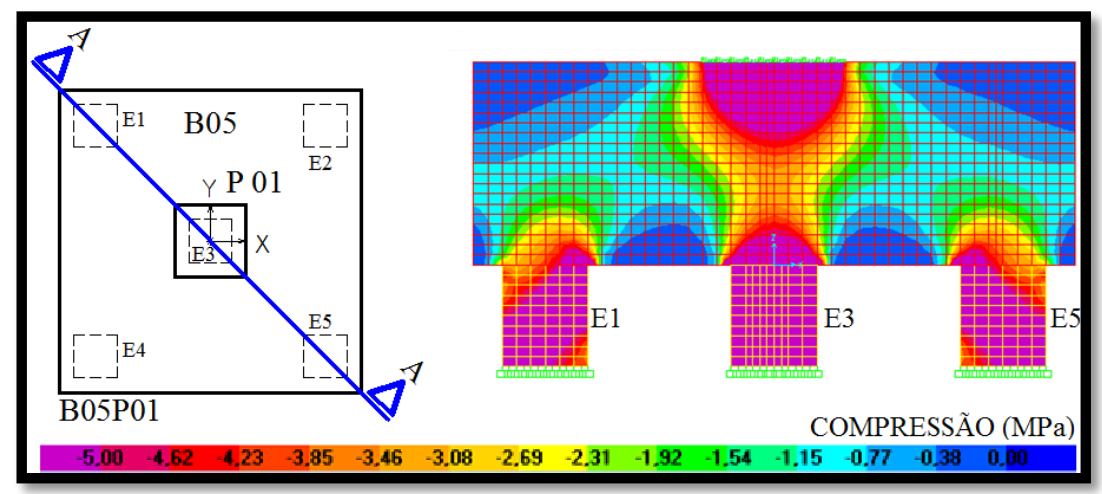

Fonte: Autores.

Figura 8: Campos de compressão ao longo do corte BB e CC da estrutura B09P01.

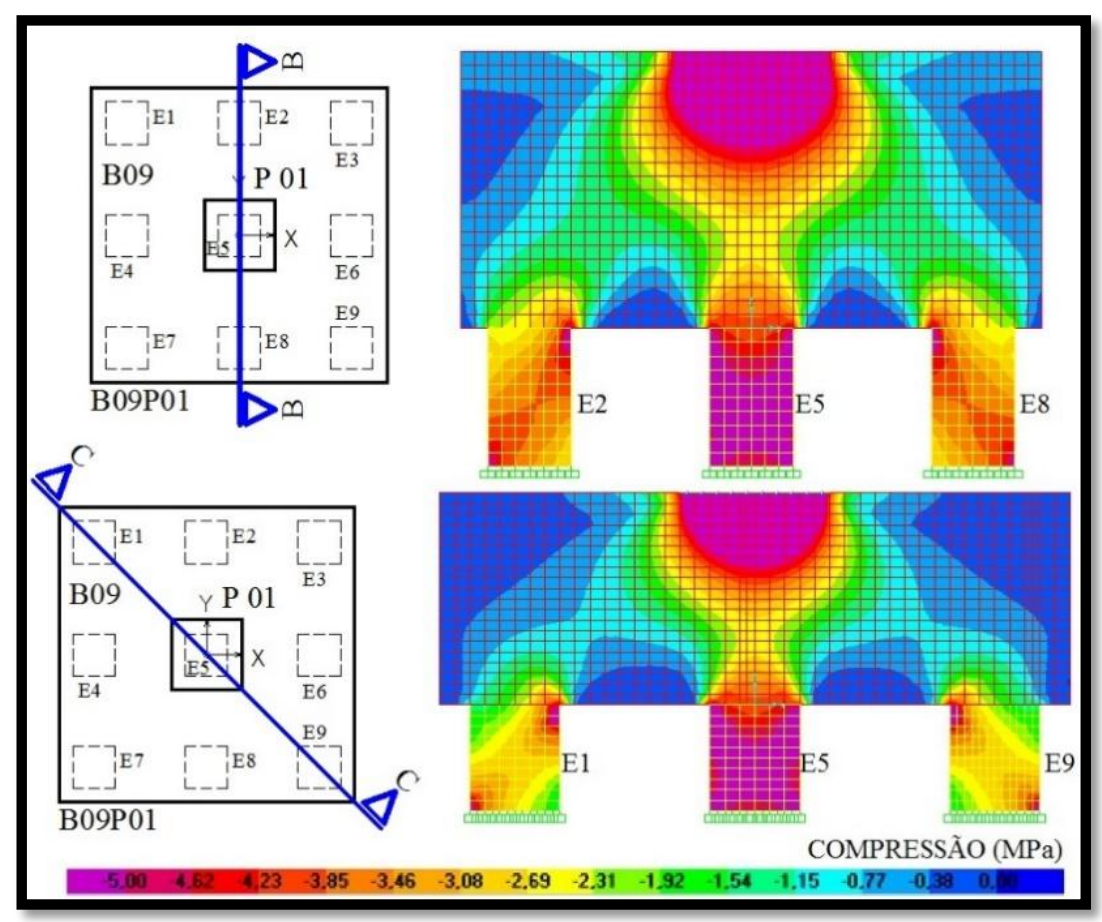

Fonte: Autores.

No bloco B09 percebe-se por meio dos cortes BB e CC que as escoras que se formam até as estacas E1, E3, E7 e E9, localizadas mais afastadas do centro, apresentam menor intensidade quando comparadas com as estacas perpendiculares ao centro do bloco (E2, E4, E6 e E8) corroborando também com suas menores reações.

Para o Pilar P02, os campos de tensões obtidos nos blocos B05 e B09 são apresentados nas Figuras 9 e 10, respectivamente. Analisando as intensidades dos campos de compressão para esta configuração de pilar percebe-se, novamente, um fluxo de tensões maior em direção à estaca central. 
Figura 9: Campos de compressão ao longo do corte DD da estrutura B05P02.

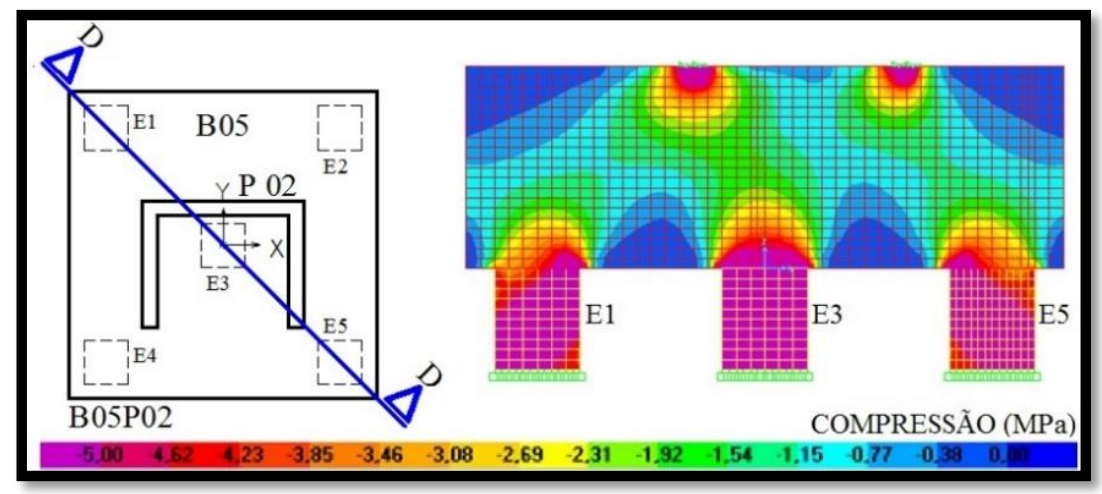

Fonte: Autores.

Figura 10: Campos de compressão ao longo dos cortes EE, FF e GG da estrutura B09P02.

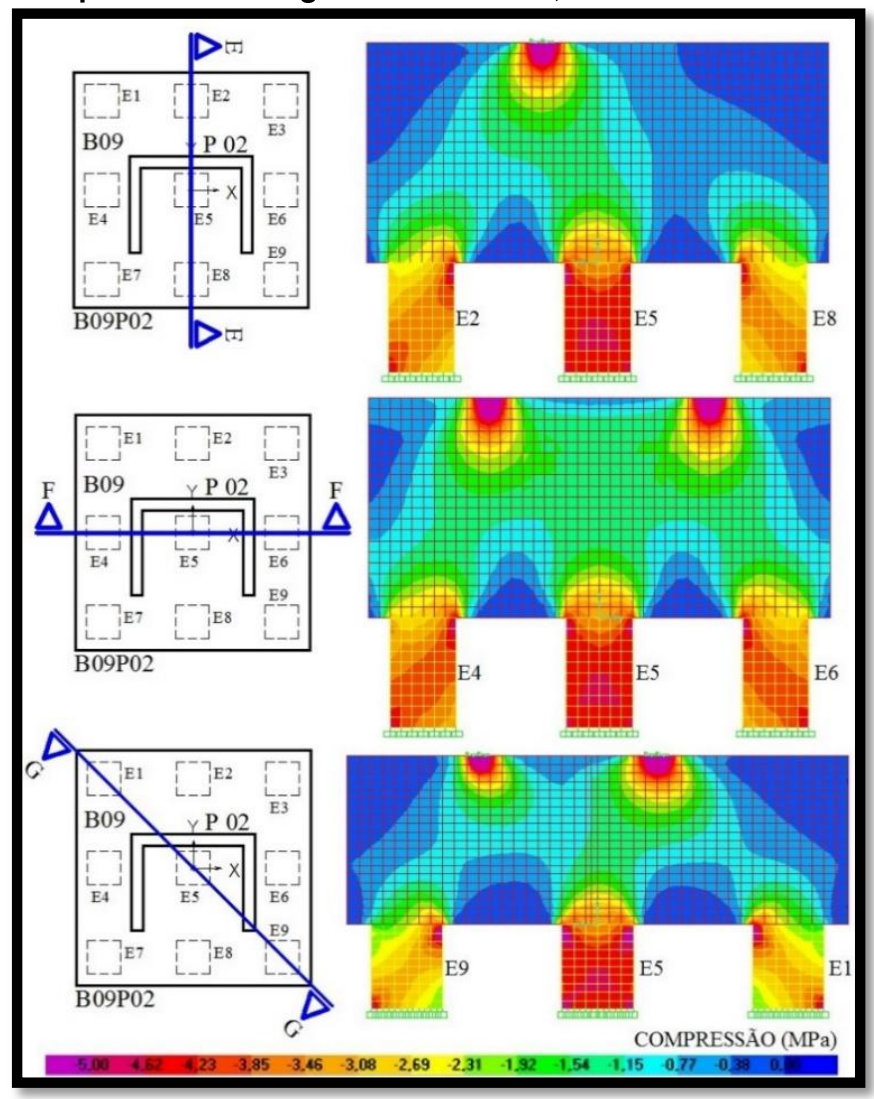

Fonte: Autores.

No corte DD da Figura 9, percebe-se pelos campos de tensões a formação de três escoras a partir da região nodal com o formato em "C". Os esforços das pontas do pilar migraram para as estacas E4 e E5 (considerar novamente a simetria do problema) e a carga aplicada próxima da região do CG se dividiu parte para a estaca E3 e parte para as estacas E1 e E2, totalizando, portanto, a formação de cinco escoras no bloco.

Para a estrutura B09P02, observando os campos de compressão da Figura 10, nota-se que as estacas E1, E2, E3, E4, E6, E7 e E9 localizadas nas proximidades do pilar recebem esforços diretos das áreas adjacentes. A carga aplicada próxima da região do CG divide os esforços para as estacas externas e para a estaca central. Já a estaca E8, mais afastada do pilar, recebe contribuição difusa originada de praticamente toda a região do pilar formando um leque que liga a base do pilar até a base da estaca, fato observado no corte EE que mostra uma parcela da carga saindo da região central do pilar em direção à estaca E8. 
Para análise dos campos de compressão do Pilar P03, foram extraídos três cortes verticais para o Bloco 05 e quatro cortes verticais para o Bloco 09. As Figuras 11 e 12 apresentam os cortes para os Blocos 05 e 09 , respectivamente.

Figura 11: Campos de compressão ao longo dos cortes HH, II e JJ da estrutura B05P03.

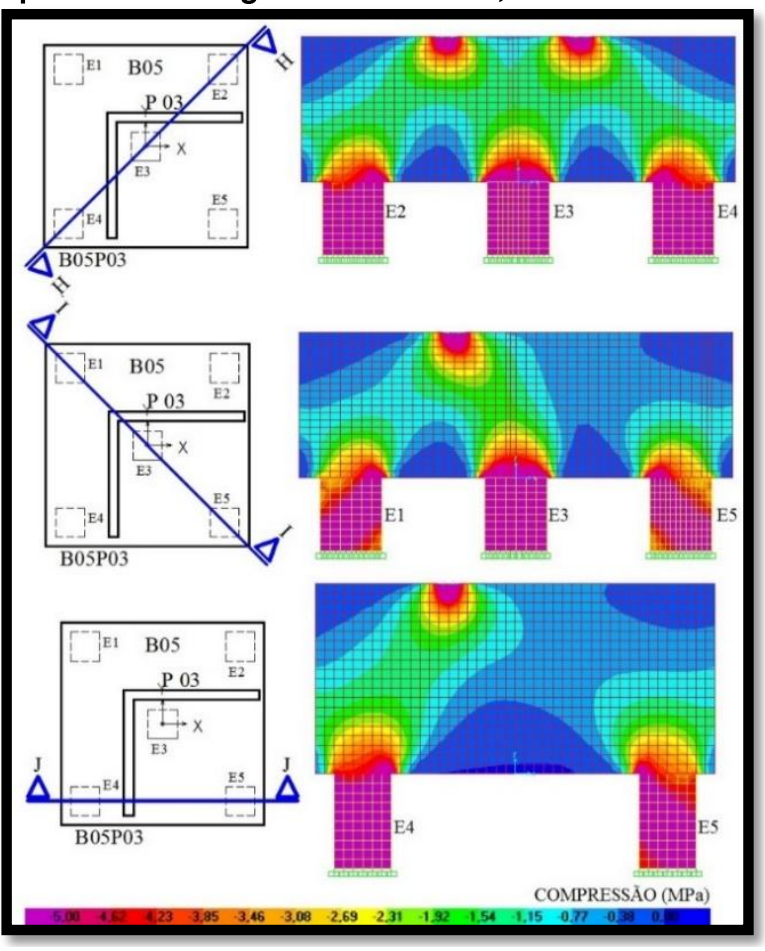

Fonte: Autores.

Figura 12: Campos de compressão ao longo dos cortes KK, LL, MM e NN da estrutura B09P03

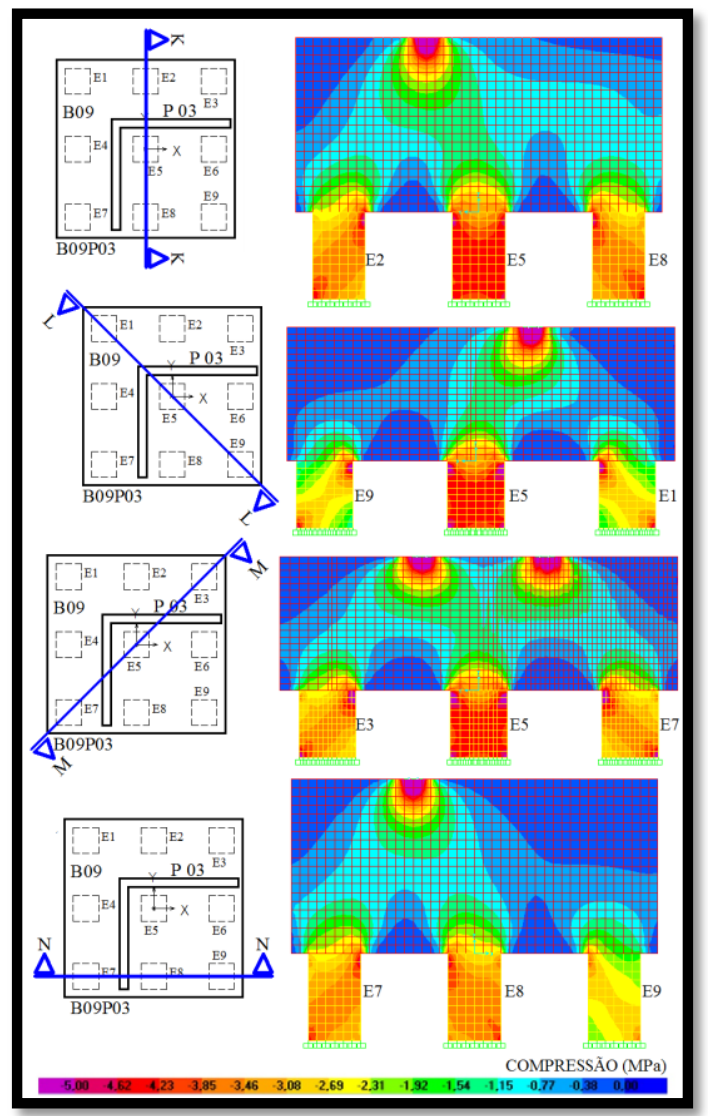


Observando os cortes da estrutura B095P03 nota-se que as estacas E1, E2 e E4 recebem contribuição das regiões do pilar mais próximas a elas, já a $\mathrm{E} 3$ recebe esforços provenientes das regiões próximas ao CG, sendo também a estaca mais carregada. Para a estaca E5, analisando os cortes que passam por ela (cortes II e JJ), pode-se notar um campo de compressão de pequena intensidade saindo do pilar P03 em ambos os pontos dos cortes e chegando até a estaca E5, indicando também uma contribuição em leque ao longo do pilar P03 para a formação da escora até a estaca E5.

Embora a formação da escora da estaca E5 seja difusa, a tensão que esta recebe é praticamente a mesma da estaca E1 que tem uma contribuição mais direta do pilar, fato que pode ser observado tanto pela intensidade dos campos de tensão do corte II quanto pelas reações das estacas Tabela 1.

Para o bloco B09P03, a estaca central também se apresentou a mais carregada e, igualmente ao bloco B05P03, pode-se notar pelos cortes LL e NN um campo de compressão de pequena intensidade saindo em leque do pilar P03 e chegando até a estaca mais afastada (E9), porém com valores próximos aos da estaca E1. Já as demais estacas receberam esforços diretos das áreas adjacentes.

Como pode ser visto anteriormente nos cortes verticais, as regiões nodais se formam na área de aplicação da carga do pilar e na cabeça das estacas, ou seja, regiões onde há transmissão de forças. Observando as Figuras 7 a 12 nota-se que na interface pilar $\mathrm{x}$ bloco é formado um bulbo de tensões acompanhando a geometria do pilar. A tensão de compressão nessa interface é da ordem de $10 \mathrm{MPa}$, sendo a maior tensão registrada. Tal valor ocorre em todos os casos pois o carregamento de 10.000 kN está aplicado em pilares com área próxima a um metro quadrado, resultando na tensão de $10 \mathrm{MPa}$.

Embora a tensão da face de aplicação seja a mesma, a geometria quadrada do pilar P01 fez com que o bulbo de tensão do nó dos blocos B05P01 e B09P01 alcançasse uma profundidade muito maior do que nas demais estruturas. Em relação as estacas, pode-se observar que o nó da estaca central de cada situação é o mais carregado, tendo em vista que este recebe o maior fluxo de carga, conforme observado também pelas reações de apoio.

Extraindo-se os campos de compressão dos nós dos pilares e das estacas centrais das seis configurações investigadas obtêm-se a Figura 13. Observando as regiões nodais, percebe-se nos pilares os valores próximos de $10 \mathrm{MPa}$. Nos nós das estacas centrais, as tensões de compressão ficaram na ordem de 8,5 MPa para os blocos com cinco estacas e 5,0 MPa para os blocos com nove estacas. 
Figura 13: Regiões nodais das seis estruturas analisadas.

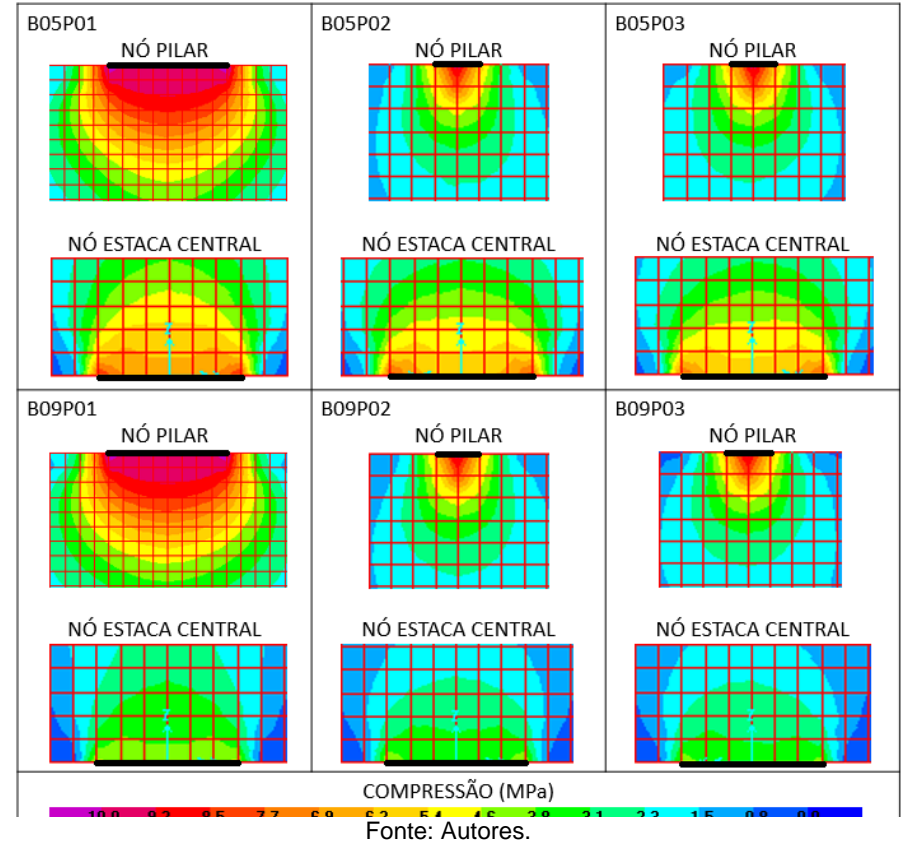

Para a análise da interface pilar x bloco, onde é aplicado o carregamento do pilar, a condição da geometria não interfere, pois, os parâmetros são a força aplicada pela área e, por estes fatores não se alterarem, o resultado é o mesmo. Já na análise do nó central, observando a Figura 13 percebe-se tensões superiores nas simulações com o pilar P01 em relação aos demais, fato ocasionado pela distribuição mais homogênea dos esforços ocorrida nas modelagens com P02 e P03, conforme observado na análise das reações de apoio.

Foram extraídos cortes horizontais mostrando a distribuição de tensões na base $(-2,00 \mathrm{~m})$ e a $10 \mathrm{~cm}$ desta (cota -1,90), nos blocos sobre cinco estacas, conforme ilustra a Figura 14. Analisando a tensão na base $(-2,00 m)$ do bloco B05P01 nota-se uma concentração de tensões de tração na ordem de 2 $\mathrm{MPa}$ no entorno da estaca central que vai reduzindo ao longo da área da base, ficando em 1,5 MPa entre as estacas periféricas. 
Figura 14: Comparação das tensões de tração nos blocos B05P01, B05P02 e B05P03.

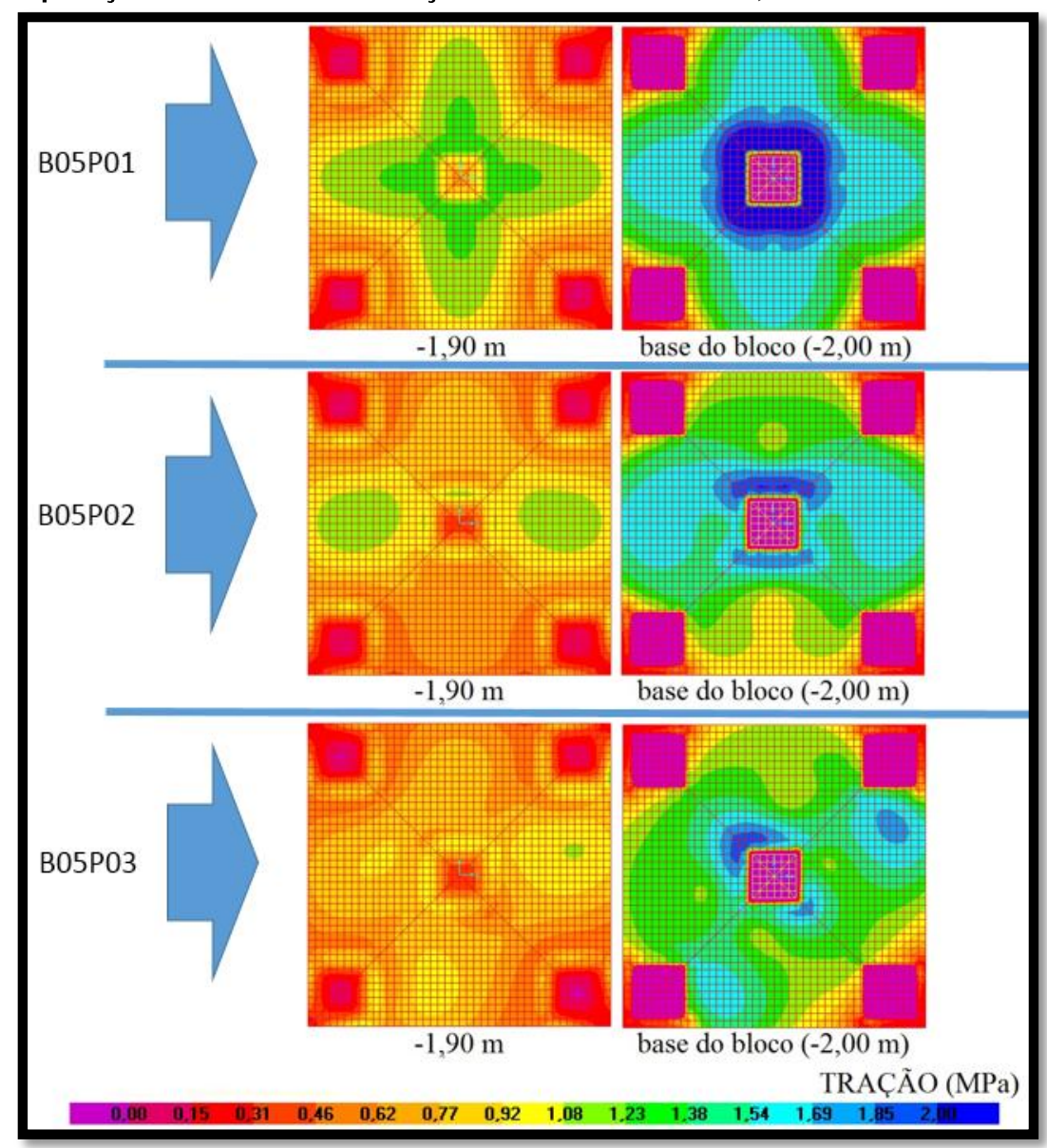

Fonte: Autores

$\mathrm{Na}$ base $(-2,00 \mathrm{~m})$ do bloco B05P02 observa-se uma área pequena com concentração de tração na ordem de $2 \mathrm{MPa}$ próximo à estaca central abaixo de uma das faces do pilar. Há também uma região com tensões na faixa de 1,5 MPa em uma região próxima da área de aplicação da carga.

$\mathrm{Na}$ B05P03 as tensões de tração atingem $2 \mathrm{MPa}$ em um pico próximo ao pilar central e, igualmente ao que ocorreu com a estrutura B05P02, também é possível ver maiores tensões nas regiões inferiores próximas da área de aplicação da carga.

Fazendo a comparação das tensões de tração nos cortes horizontais da estrutura B05P01 em relação as outras duas, nota-se que houve uma redução das tensões de tração na área central. Tal fato é bem caracterizado quando se analisa as áreas com tração superior a $2 \mathrm{MPa}$ (azul escuro) na base dos blocos e as áreas com tensão entre 1,08 e 1,38 MPa (verde) no corte em -1,90 m.

Também foram extraídos cortes horizontais mostrando a distribuição de tensões na base $(-2,00 \mathrm{~m})$ e a $10 \mathrm{~cm}$ desta (cota -1,90), para os blocos sobre nove estacas, conforme ilustra a Figura 15. Analisando a tensão na base do bloco B09P01 nota-se uma concentração de tração na ordem de $2 \mathrm{MPa}$ no entorno da estaca central, igualmente ao que ocorreu na estrutura B05P01 porém, nessa estrutura, uma grande região entre as estacas ficou com tensões distribuídas na ordem de 1,08 a 1,38 MPa, diferente da grande área de tensões entre 1,54 a 1,69 MPa ocorridas no bloco com cinco estacas. 
Figura 15: Comparação das tensões de tração nos blocos B09P01, B09P02 e B09P03.

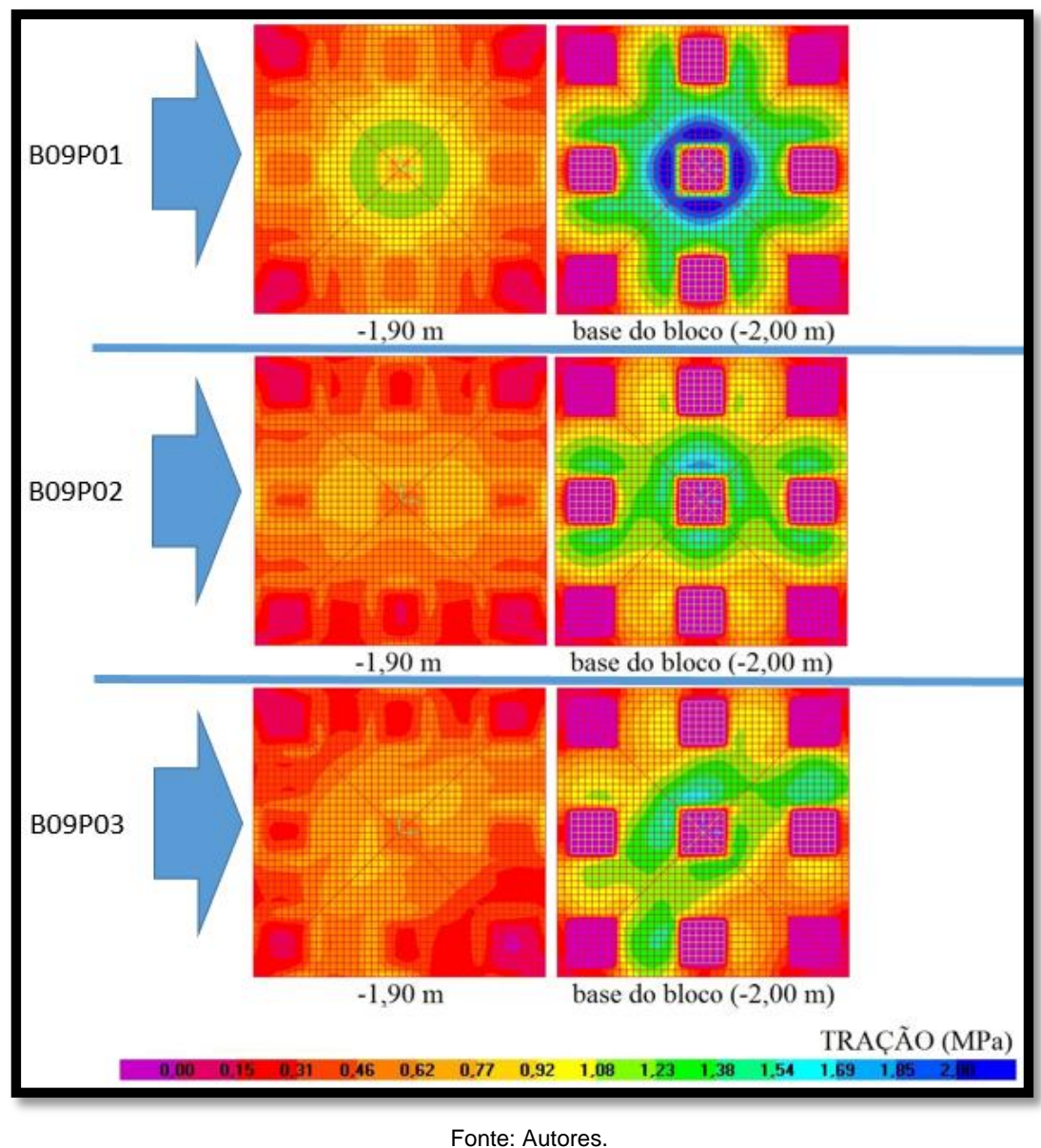

Para a estrutura B09P02, observando os valores tem-se um pico de 1,72 MPa próximo à estaca central e uma faixa entre as estacas E4, E5 e E6 com tensões na ordem de 1,08 a 1,38 MPa. Já na B09P03 percebe-se um pico de 1,60 MPa próximo da estaca central e uma região na diagonal do bloco com tensões entre 1,08 e 1,38 MPa, região localizada abaixo do pilar em "L".

Fazendo a comparação das tensões de tração nos cortes horizontais da estrutura B09P01 em relação as outras duas, nota-se que, assim como no bloco B05, também houve uma redução das tensões de tração na área central. Tal fato é bem caracterizado quando se analisa as áreas com tração superior a $2 \mathrm{MPa}$ (azul escuro) na base dos blocos e as áreas com tensão entre 1,08 e 1,23 MPa (verde) no corte em $-1,90 \mathrm{~m}$.

Dessa análise das tensões da base observa-se então que a variação do formato do pilar alterou as tensões registradas no interior da estrutura. Tanto a geometria em "C" quanto a em "L" provocou tensões mais elevadas nas regiões abaixo do local de aplicação da carga, porém, ao se comparar tais tensões com as registradas na simulação com pilar de seção quadrada equivalente, as tensões registradas na simplificação foram mais elevadas.

Para quantificação das tensões de tração ao longo da altura do bloco, calculou-se o valor dos esforços em cortes passando em seções críticas identificadas em cada estrutura. Devido aos baixos valores da tensão de tração nas camadas superiores do bloco entre a base do pilar e a profundidade média (-1,00 m), tensões estas inferiores a $0,3 \mathrm{MPa}\left(1,2 \%\right.$ do $\left.\boldsymbol{f}_{\boldsymbol{c k}}\right)$, restringiu-se a quantificação das tensão de tração para as atuantes entre a cota $-1,00 \mathrm{~m}$ até a $-2,00 \mathrm{~m}$ (base do bloco). A Tabela 4 procura ilustrar um resumo das forças de tração obtidas para os blocos simulados, de maneira que pode ser obtida uma estimativa para as armaduras resistentes. 
A Tabela 4 mostra a mínima, média e máxima força de tração em $\mathrm{kN} / \mathrm{m}$ registradas ao longo de cada estrutura, bem como a resultante ao longo de toda zona tracionada em $\mathrm{kN}$. Analisando os resultados percebe-se que os maiores valores, tanto entre as estruturas de cinco quando de nove estacas, foram os registrados para o pilar de seção quadrada equivalente P01. Ou seja, houve uma redução das forças mínima, média, máxima e total atuantes na zona tracionada das estruturas de geometria complexa em relação as do pilar quadrado equivalente, nas duas configurações de estacas estudadas. Em relação a força de tração total a redução observada variou de $14,49 \%$ da B05P02 até $34,17 \%$ na B09P03.

Tabela 4: Tensões de tração nos blocos estudados.

\begin{tabular}{llllll}
\hline & \multicolumn{5}{c}{ FORÇA DE TRAÇÃO } \\
\cline { 2 - 6 } BLOCO & $\begin{array}{l}\text { MíNIMA } \\
(\mathrm{kN} / \mathrm{m})\end{array}$ & $\begin{array}{l}\text { MÉDIA } \\
(\mathrm{kN} / \mathrm{m})\end{array}$ & $\begin{array}{l}\text { MÁXIMA } \\
(\mathrm{kN} / \mathrm{m})\end{array}$ & $\begin{array}{l}\text { TOTAL } \\
(\mathrm{kN})\end{array}$ & $\begin{array}{l}\text { VARIAÇÃO EM } \\
\text { RELAÇÃO A TOTAL }(\%)\end{array}$ \\
\hline B05P01 & 695,5 & 816,2 & 1027,5 & 3428,0 & Referência \\
B05P02 & 561,5 & 697,9 & 785,0 & 2931,1 & $-14,49$ \\
B05P03 & 581,5 & 634,1 & 745,0 & 2663,4 & $-22,30$ \\
B09P01 & 516,7 & 696,2 & 883,2 & 2923,9 & Referência \\
B09P02 & 398,5 & 518,2 & 638,0 & 2176,4 & $-25,57$ \\
B09P03 & 298,0 & 458,3 & 563,0 & 1924,7 & $-34,17$ \\
\hline
\end{tabular}

Fonte: Autores.

Dessa maneira, observou-se que as configurações complexas dos pilares em estudo, para as duas configurações de estacas estudadas, resultam em forças de tração inferiores quando comparados ao campo de um pilar de geometria quadrada equivalente. Dessa forma, para estes casos, o dimensionamento pela seção simplificada resulta em tirantes com maior área de aço do que a área que seria obtida com o uso da geométrica dos pilares complexos. Assim, pelas análises realizadas, a utilização de tal simplificação conduz a um dimensionamento a favor da segurança. Isso ocorre porque com o uso da aplicação da carga no formato complexo do pilar, as escoras formadas ligando o pilar as estacas são menos inclinadas, gerando tirantes com menor esforço de tração.

De maneira a comparar os resultados obtidos com a utilização de análises tridimensionais elásticas com o programa SAP2000, os blocos também foram investigados com a utilização do programa CAD/TQS (TQS INFORMÁTICA, 2017). O referido programa utiliza o Método Simplificado das Bielas (Blévot), isto é, o cálculo dos blocos é realizado a partir da força normal equivalente, ou seja, a força normal máxima em todas as estacas, obtida a partir de todos os casos de carregamentos fornecidos. Essa força normal equivalente é então multiplicada pelo número de estacas do bloco, de maneira a se obter uma força equivalente atuante no pilar. A Figura 16 ilustra os blocos simulados no programa CAD/TQS e exportados para o programa AUTODESK REVIT (AUTODESK, 2018) para melhor visualização. 
Figura 16: Blocos de 5 e 9 estacas simulados no programa CAD/TQS e exportados para o programa AUTODESK REVIT para melhor visualização.

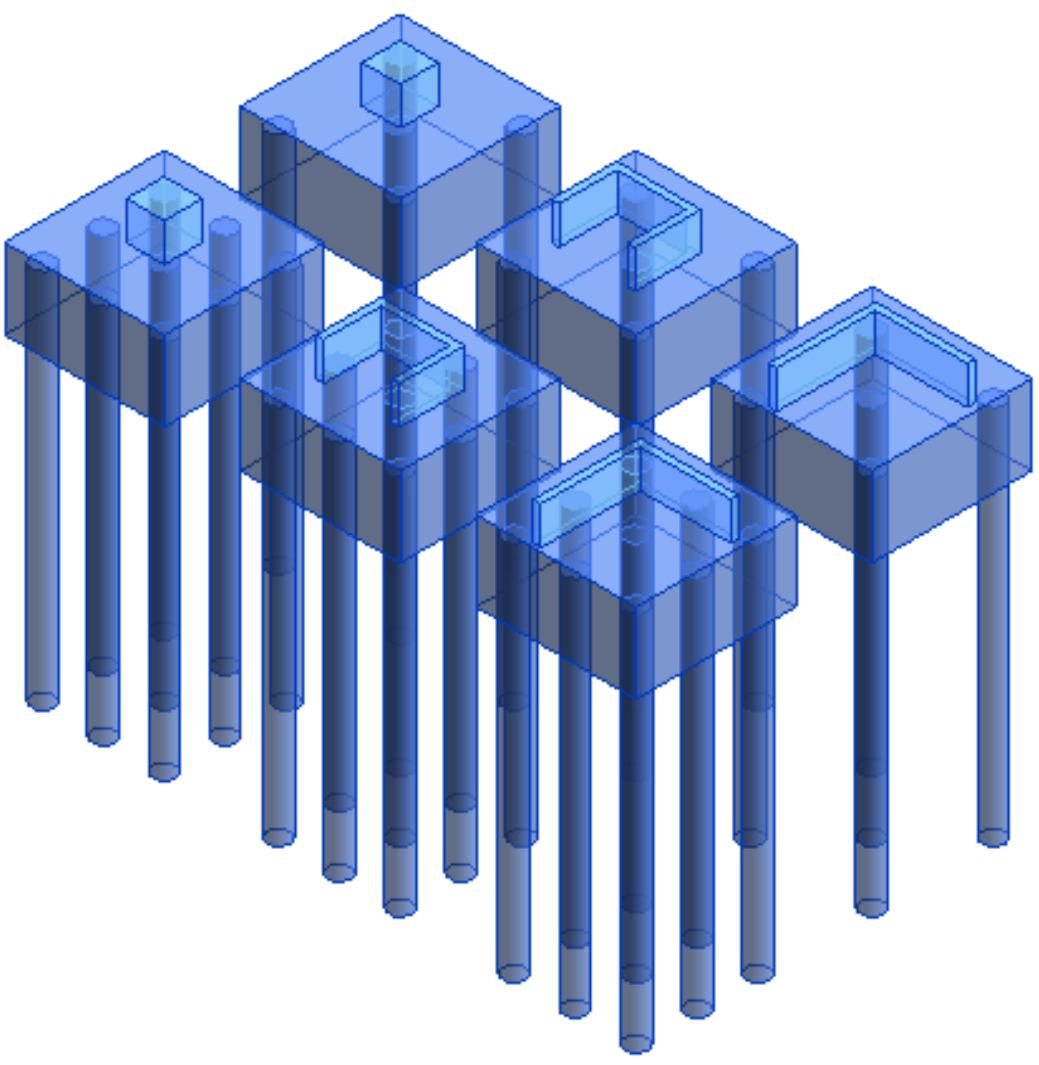

Fonte: Autores.

Para os blocos de cinco estacas, a máxima tensão característica atuante nas bielas junto ao pilar obtida com o auxílio do programa CAD/TQS foi de 21,25 MPa, enquanto a máxima tensão característica atuante nas bielas junto à cabeça das estacas foi de 16,42 MPa. Deve-se observar que o programa CAD/TQS normalmente informa essas tensões em valores de cálculo e, de maneira a se obter valores característicos, configurou-se no arquivo de critérios para blocos os coeficientes $\gamma \mathrm{d}$ e $\gamma \mathrm{n}$ como sendo unitários.

Para os blocos de 9 estacas, as tensões características atuantes nas bielas junto ao pilar e às estacas foram de 16,64 MPa e 7,15 MPa. Deve-se observar que como as tensões são calculadas por um modelo simplificado de treliça, as tensões estimadas com o programa CAD/TQS foram maiores do que aquelas obtidas através do modelo elástico tridimensional utilizando o programa SAP2000.

A Tabela 5 apresenta uma estimativa das armaduras de tração nas bases dos blocos a partir das tensões médias características de tração apresentadas na Tabela 4. Para obtenção da força total de tração em cada direção, multiplicou-se a tensão média pela largura dos blocos $(4,20 \mathrm{~m})$. Em seguida, com os valores da força total de tração foi possível obter a armadura total nas direções assumindo-se os valores de coeficientes de segurança recomendados pela ABNT NBR 6118 (2014), isto é, multiplicando-as as forças por $\gamma \mathrm{f}=1,4$ e $\gamma \mathrm{n}=1,1$, bem como dividindo a tensão característica do aço pelo coeficiente $\gamma s=1,15$. No programa CAD/TQS definiu-se o critério de distribuição uniforme das armaduras para compatibilidade entre os modelos investigados. 
Tabela 5: Armações principais distribuídas para os blocos estudados.

\begin{tabular}{llll}
\hline BLOCO & $\begin{array}{l}\text { FORÇA MÉDIA } \\
\text { CARACTERISTIC } \\
\text { A (kN/m) }\end{array}$ & $\begin{array}{l}\text { ARMADURA } \\
\text { DISTRIBUíDA } \\
(\mathbf{c m})\end{array}$ & $\begin{array}{l}\text { ARMADURA DISTRIBUíDA } \\
\text { NECESSÁRIA }\end{array}$ \\
\hline B05P01 & 816,2 & 121,42 & $\phi 20 \mathrm{~mm} \mathrm{c} / 10 \mathrm{~cm}$ \\
B05P02 & 697,9 & 103,82 & $\phi 20 \mathrm{~mm} \mathrm{c} / 12 \mathrm{~cm}$ \\
B05P03 & 634,1 & 94,33 & $\phi 20 \mathrm{~mm} \mathrm{c} / 14 \mathrm{~cm}$ \\
CAD/TQS* (5 estacas) & - & 116,10 & $\phi 20 \mathrm{~mm} \mathrm{c} / 10 \mathrm{~cm}$ \\
B09P01 & 696,2 & 103,57 & $\phi 20 \mathrm{~mm} \mathrm{c/} 12 \mathrm{~cm}$ \\
B09P02 & 518,2 & 77,09 & $\phi 20 \mathrm{~mm} \mathrm{c/} 16 \mathrm{~cm}$ \\
B09P03 & 458,3 & 68,18 & $\phi 20 \mathrm{~mm} \mathrm{c/} 19 \mathrm{~cm}$ \\
CAD/TQS* (9 estacas) & - & 165,40 & $\phi 25 \mathrm{~mm}$ c/5 cm \\
\hline
\end{tabular}

Conforme pode-se observar pela Tabela 5 , o procedimento simplificado definido no programa CAD/TQS 20 leva a um número maior de armaduras do que aquelas que seriam obtidas utilizando um modelo tridimensional, tanto para os blocos de cinco quanto para nove estacas. Deve-se observar que no caso do bloco de nove estacas essa tendência foi ainda maior.

Deve-se observar que do ponto de vista do Método das Bielas e do item 22.7.4.1.1 da ABNT NBR 6118 (2014), o adequado seria concentrar mais de $85 \%$ das armaduras de flexão na cabeça das estacas. No entanto, apenas para fins de comparação das armaduras de tração obtidas pelo programa SAP2000 com àquelas obtidas pelo programa CAD/TQS, assumiu-se uma configuração distribuída de armaduras.

\section{Conclusões}

$\mathrm{Na}$ análise dos diferentes pilares estudados percebeu-se que a consideração de geometria complexa gerou uma distribuição mais homogênea dos esforços no interior da estrutura, tanto no bloco sobre cinco estacas quando para o bloco sobre nove estacas.

Em consequência de uma melhor distribuição dos esforços, os pilares de geometria complexa apresentaram campos de tração inferiores quando comparados ao campo de um pilar de seção quadrada equivalente. Isso ocorreu devido a condição de aplicação da carga mais afastada do CG do pilar ter gerado escoras menos inclinadas, que resultaram em tirantes com menor esforço de tração.

Assim, as estruturas estudadas corroboraram para a aceitação da simplificação da geometria do pilar complexo por pilar de seção quadrada, visto terem conduzido para um dimensionamento a favor da segurança.

Comparando os resultados obtidos com o programa CAD/TQS com o programa SAP2000, observou-se que as tensões e a quantidade de armaduras principais distribuídas obtidas com o programa CAD/TQS, baseados em um modelo simplificado de treliça, são maiores do que aqueles observados com o programa SAP2000. Deve-se observar que no programa CAD/TQS, em função da definição de um pilar equivalente, as respostas são idênticas para os casos de pilar quadrado, em $L$ ou em $U$.

As análises numéricas demonstraram que o cálculo mais preciso com a utilização da geometria real do pilar pode conduzir a uma redução do consumo de armadura e uma avaliação mais realista do nível de tensão atuante nas bielas e regiões nodais. No entanto, a simulação numérica contemplando as estacas, o bloco e a geometria complexa do pilar, pode não justificar tal benefício, em vista das dificuldades de simulação, da experiência requerida e do tempo de análise incompatível com o tempo 
de entrega de projeto normalmente requerido no dia-a-dia dos escritórios de cálculo.

Finalmente, as simulações ora aqui efetuadas foram realizadas para o caso simples de carga centrada, observando que a presença de momentos fletores atuantes nos pilares poderia levar à obtenção de resultados ainda mais distantes entre aqueles obtidos com modelo elástico tridimensional e o modelo simplificado de treliça.

\section{Referências Bibliográficas}

ADEBAR, P.; KUCHMA, D.; COLLINS, M. P. Strut-and-Tie Models for the Design of Pile Caps: An Experimental Study. ACI Structural Journal, v.87, n.1, p.81-92, 1990.

ACI COMMITTEE 318. Building Code Requirements for Structural Concrete (ACl 318-19) and Commentary (ACl 318R-2019). Detroit, MI: ACl Comitee 318, 2019.

ASSOCIAÇÃO BRASILEIRA DE NORMAS TÉCNICAS. NBR 6118: Projeto de estruturas de concreto - Procedimento. Rio de Janeiro: ABNT, 2014.

AUTODESK. Autodesk Revit 2018 User's Manual. Disponível em http://help.autodesk.com/view/RVT/2018/PTB/

BLEVOT, J.; FRÉMY, R. Semelles Sur Pieux. Annales de L'institut Tecnique Du Bâtiment et des Travaux Publics, Paris, v.20, n. 230, p. 224-273, 1967.

CHAN, T. K.; POH, C. K. Behaviour of Precast Reinforced Concrete Pile Caps. Construction and Building Materials, n.14, pp. 73-78, 2000.

COMPUTERS AND STRUCTURES INC (CSI). Analysis reference manual: For SAP2000, ETABS, SAFE and CSiBridge. Berkeley, California, USA. 2013.

DELALIBERA, R. G. Análise numérica e experimental de blocos de concreto armado sobre duas estacas submetidos à ação de força centrada e excêntrica. 2006, 332. Tese (Doutorado em Engenharia de Estruturas). Universidade de São Paulo, São Carlos, 2006.

IYER, P. K.; SAM, C. Three-Dimensional Analysis of Pile Caps. Computers and Structures, v.42, n.3, pp. 395-411, 1992.

MIGUEL, G. M. Análises experimental e numérica de blocos sobre três estacas. 2000, 242. Tese (Doutorado em Engenharia de Estruturas). Universidade de São Paulo, São Carlos, 2000.

SAM, C.; IYER, P. K. Nonlinear Finite Element Analysis of Reinforced Concrete Four-Pile Caps. Computers \& Structures, v.57, n.4, pp.605-622, 1995.

SCHÄFER, K.; SCHLAICH, J. Design and Detailing of Structural Concrete Using Strut-and-Tie Models. The Structural Engineer, v. 69, n. 06, p.113-125, 1991

SOUZA, R. A. Concreto Estrutural: Análise e dimensionamento de elementos com descontinuidade. 2004, 379. Tese (Doutorado em Engenharia). Universidade de São Paulo, São Paulo, 2004.

SOUZA, R. A.; BITTENCOURT, T. N. Non-Linear Analysis of Four-Pile Caps. Revista IBRACON de Estruturas, v. 02, p. 310-319, 2006.

SOUZA, R. A; KUCHMA, D. A. ; PARK, J. ; BITTENCOURT, T. N. Non-Linear Finite Element Analysis of Four-Pile Caps Supporting Columns Subjected to Generic Loading. Computers and Concrete, an International Journal (Print), v. 4, p. 363-376, 2007

SOUZA, R. A.; KUCHMA, D.; PARK, J. W.; BITTENCOURT, T. Adaptable strut-and-tie model for design and verification of four-pile caps. ACI Structural Journal, v. 106, n. 2, p. 142-150, 2009.

TQS INFORMÁTICA. CAD/FUNDAÇÕES - Manual Teórico (Versão 20.7.11). São Paulo, São Paulo, Brasil, 2017. 